\title{
REVISITING THE SUPPLY-SIDE EFFECTS OF GOVERNMENT SPENDING UNDER
} INCOMPLETE MARKETS

\author{
George-Marios Angeletos \\ Vasia Panousi
}

Working Paper 13136

http://www.nber.org/papers/w13136

\author{
NATIONAL BUREAU OF ECONOMIC RESEARCH \\ 1050 Massachusetts Avenue \\ Cambridge, MA 02138
}

May 2007

The views expressed herein are those of the author(s) and do not necessarily reflect the views of the National Bureau of Economic Research.

(C) 2007 by George-Marios Angeletos and Vasia Panousi. All rights reserved. Short sections of text, not to exceed two paragraphs, may be quoted without explicit permission provided that full credit, including $\odot$ notice, is given to the source. 
Revisiting the Supply-Side Effects of Government Spending Under Incomplete Markets

George-Marios Angeletos and Vasia Panousi

NBER Working Paper No. 13136

May 2007

JEL No. E13,E6,H3

\section{ABSTRACT}

This paper revisits the macroeconomic effects of government consumption in the neoclassical growth model augmented with idiosyncratic investment (or entrepreneurial) risk. Under complete markets, a permanent increase in government consumption has no long-run effect on the interest rate, the capital-labor ratio, and labor productivity, while it increases work hours due to the familiar negative wealth effect. These results are upset once we allow for incomplete markets. The very same negative wealth effect now causes a reduction in risk taking and investment. This in turn leads to a lower risk-free rate and, under certain conditions, also to a lower capital-labor ratio, lower productivity and lower wages.

George-Marios Angeletos

Department of Economics

MIT

50 Memorial Drive, E52-251

Cambridge, MA 02142

and NBER

angelet@mit.edu

Vasia Panousi

Dept of Economics

MIT

50 Memorial Drive, E52-251

Cambridge, MA 02142

panousi@mit.edu 


\section{Introduction}

Studying the impact of government spending on macroeconomic outcomes is one of the most celebrated policy exercises within the neoclassical growth model; it is important for understanding the business-cycle implications of fiscal policy, the macroeconomic effects of wars, and the crosssection of countries. Some classics include Hall (1980), Barro (1981, 1989), Aiyagari, Christiano and Eichenbaum (1992), Baxter and King (1993), and McGrattan and Ohanian (1999, 2006).

These studies have all maintained the convenient assumption of complete markets, abstracting from the possibility that agents' saving and investment decisions - and hence their reaction to changes in fiscal policy - may crucially depend on the extent of risk sharing within the economy. This paper contributes towards filling this gap. It revisits the macroeconomic effects of government consumption within an incomplete-markets variant of the neoclassical growth model.

Apart from introducing undiversified idiosyncratic risk in production and investment, all other ingredients of our model are the same as in the canonical neoclassical growth model: firms operate neoclassical constant-returns-to-scale technologies, households have standard CRRA/CEIS preferences, and markets are competitive. The focus on idiosyncratic production/investment risk is motivated by two considerations. First, this friction is empirically relevant. This is obvious for less developed economies. But even in the United States, privately-owned firms account for about one half of aggregate production and employment. Furthermore, the typical investor - the median rich household-holds a very undiversified portfolio, more than one half of which is allocated to private equity. ${ }^{1}$ And second, as we explain next, this friction upsets some key predictions of the standard neoclassical paradigm.

In the standard neoclassical paradigm, the steady-state values of the capital-labor ratio, productivity (output per work hour), the wage rate, and the interest rate, are all pinned down by the equality of the marginal product of capital with the discount rate in preferences. As a result, any change in the level of government consumption, even if it is permanent, has no effect on the long-run values of these variables. ${ }^{2}$ On the other hand, because higher spending for the government means lower wealth for the households, a permanent increase in government consumption raises labor supply. It follows that employment (work hours) and output increase both in the short run and in the long run, so as to keep the long-run levels of capital intensity and productivity unchanged.

The picture is quite different once we allow for incomplete markets. The same wealth effect that, in response to an increase in government consumption, stimulates labor supply in the standard paradigm, now also discourages investment. This is simply because risk taking, and hence

\footnotetext{
${ }^{1}$ See Quadrini (2000), Gentry and Hubbard (2000), Carroll (2000), and Moskowitz and Vissing-Jørgensen (2002). Also note that idiosyncratic investment risks need not be limited to private entrepreneurs; they may also affect educational and occupational choices, or the production decisions that CEO's make on behalf of public corporations.

${ }^{2}$ This, of course, presumes that the change in government consumption is financed with lump-sum taxes. The efficiency or redistributive considerations behind optimal taxation is beyond the scope of this paper.
} 
investment, is sensitive to wealth. We thus find very different long-run effects. First, a permanent increase in government consumption necessarily reduces the risk-free interest rate. And second, unless the elasticity of intertemporal substitution is low enough, it also reduces the capital-labor ratio, productivity, and wages.

The effect on the risk-free rate is an implication of the precautionary motive: a higher level of consumption for the government implies a lower aggregate level of wealth for the households, which is possible in steady state only with a lower interest rate. A lower interest rate, however, does not necessarily imply a higher capital-labor ratio. This is because market incompleteness introduces a wedge between the risk-free rate and the marginal product of capital. Furthermore, because of diminishing absolute risk aversion, the lower the level of wealth, the higher will be the risk premium on investment, and hence this wedge. It follows that, in response to an increase in government consumption, the capital-labor ratio can fall even if the interest rate also falls. Indeed, a sufficient condition for this to be the case is that the elasticity of intertemporal substitution is sufficiently high relative to the income share of capital - a condition easily satisfied for plausible calibrations of the model.

Turning to employment and output, there are two opposing effects. On the one hand, as with complete markets, the negative wealth effect on labor supply contributes towards higher employment and output. On the other hand, unlike complete markets, the reduction in capital intensity, productivity, and wages contributes towards lower employment and output. Depending on the income and wage elasticities of labor supply, either of the two effects can dominate.

The deviation from the standard paradigm is significant, not only qualitatively, but also quantitatively. For our preferred parametrizations of the model, the following hold. First, the elasticity of intertemporal substitution is comfortably above the critical value that suffices for an increase in government consumption to reduce the long-run levels of the capital-labor ratio, productivity, and wages. Second, the negative effects on these variables are quantitatively significant: a $1 \%$ increase in government spending under incomplete markets has the same impact on capital intensity and labor productivity as a $0.5 \%-0.6 \%$ increase in capital-income taxation under complete markets. Third, these effects mitigate, but do not fully offset, the wealth effect on labor supply. Finally, the welfare consequences are non-trivial: the welfare cost of a permanent $1 \%$ increase in government consumption is three times larger under incomplete markets than under complete markets.

The main contribution of the paper is thus to highlight how wealth effects on investment due to financial frictions can significantly modify the supply-side channel of fiscal policy. In our model, these wealth effects emerge from idiosyncratic risk along with diminishing absolute risk aversion; in other models, they could emerge from borrowing constraints. Also, such wealth effects are relevant for both neoclassical and Keynesian models. In this paper we follow the neoclassical tradition, not because of any belief on which paradigm best fits the data, but rather because this clarifies 
the value of our contribution: whereas wealth effects are central to the neoclassical approach with regard to labor supply, they have been mute with regard to investment.

To the best of our knowledge, this paper is the first to study the macroeconomic effects of government consumption in an incomplete-markets version of the neoclassical growth paradigm. ${ }^{3}$ The particular framework we employ for this purpose is a continuous-time variant of the one introduced in Angeletos (2007). That paper studied how idiosyncratic capital-income risk affects aggregate saving, and contrasted this with the impact of labor-income risk in Bewley type models (Aiyagari, 1994; Huggett, 1997; Krusell and Smith, 1998). Other papers that introduce idiosyncratic investment or entrepreneurial risk in the neoclassical growth model include Angeletos and Calvet (2006), Buera and Shin (2007), Caggeti and De Nardi (2006), Covas (2006), and Meh and Quadrini (2006). ${ }^{4}$ The novelty of our paper is to study the implications for fiscal policy in such an environment.

The rest of the paper is organized as follows. Section 2 introduces the basic model, Section 3 characterizes its equilibrium, and Section 4 analyzes its steady state. The basic model fixes labor supply so as to focus on the most novel results of the paper, namely the steady-state effects of government consumption on the interest rate and the capital-labor ratio. Section 5 then turns to three extensions that endogenize labor supply. Section 6 examines the dynamic response of the economy to a permanent change in government consumption. Section 7 concludes.

\section{The basic model}

Time is continuous, indexed by $t \in[0, \infty)$. There is a continuum of infinitely-lived households, indexed by $i$ and distributed uniformly over [0,1]. Each household is endowed with one unit of labor, which it supplies inelastically in a competitive labor market. Each household also owns and runs a firm, which employs labor in the competitive labor market but can only use the capital stock invested by the particular household. ${ }^{5}$ Households cannot invest in other households' firms and cannot otherwise diversify away from the shocks hitting their firms, but can freely trade a riskless bond. Finally, all uncertainty is purely idiosyncratic, and hence all aggregates are deterministic.

\footnotetext{
${ }^{3}$ A related, but different, exercise is conducted in Heathcote (2005). That paper studies the impact of a change in the timing of taxes in a Bewley-type model like Aiyagari's (1994), where borrowing constraints limit the ability of households to smooth consumption, thus breaking Ricardian equivalence, but where market incompleteness does not impact the production side of the economy. In our paper, instead, the key friction is on the production side. Moreover, deviations from Ricardian equivalence are not considered: our model allows households to freely trade a riskless bond, thus ensuring that the timing of taxes has no effect on allocations.

${ }^{4}$ Related is also Obstfeld (1994), which assumes a continuous-time Epstein-Zin specification as this paper, but with an $A K$ technology.

${ }^{5}$ We can think of a household as a couple, with the wife running the family business and the husband working in the competitive labor market (or vice versa). The key assumption, of course, is only that the value of the labor endowment of each household is pinned down by the competitive wage and is not subject to idiosyncratic risk.
} 


\subsection{Households and firms}

The financial wealth of household $i$, denoted by $x_{t}^{i}$, is the sum of its holdings in private capital, $k_{t}^{i}$, and the riskless bond, $b_{t}^{i}$ :

$$
x_{t}^{i}=k_{t}^{i}+b_{t}^{i}
$$

The evolution of $x_{t}^{i}$ is given by the household budget:

$$
d x_{t}^{i}=d \pi_{t}^{i}+\left[R_{t} b_{t}^{i}+\omega_{t}-T_{t}-c_{t}^{i}\right] d t
$$

where $d \pi_{t}^{i}$ is the household's capital income (i.e., the profits it enjoys from the private firm it owns), $R_{t}$ is the interest rate on the riskless bond, $\omega_{t}$ is the wage rate, $T_{t}$ is the lump-sum tax, and $c_{t}^{i}$ is the household's consumption. Finally, the familiar no-Ponzi game condition is also imposed.

Whereas the sequences of prices and taxes are deterministic (due to the absence of aggregate risk), firm profits, and hence household capital income, are subject to undiversified idiosyncratic risk. In particular,

$$
d \pi_{t}^{i}=\left[F\left(k_{t}^{i}, n_{t}^{i}\right)-\omega_{t} n_{t}^{i}-\delta k_{t}^{i}\right] d t+\sigma k_{t}^{i} d z_{t}^{i}
$$

Here, $n_{t}^{i}$ is the amount of labor the firm hires in the competitive labor market, $F$ is a constantreturns-to-scale neoclassical production function, and $\delta$ is the mean depreciation rate. Idiosyncratic risk is introduced through $d z_{t}^{i}$, a standard Wiener process that is i.i.d. across agents and across time. This can be interpreted either as a stochastic depreciation shock or as a stochastic productivity shock, the key element being that it generates risk in the return to capital. The scalar $\sigma$ measures the amount of undiversified idiosyncratic risk and can be viewed as an index of market incompleteness, with higher $\sigma$ corresponding to a lower degree of risk sharing (and $\sigma=0$ corresponding to complete markets). Finally, without serious loss of generality, we assume a Cobb-Douglas specification for the technology: $F(k, n)=k^{\alpha} n^{1-\alpha}$ with $\alpha \in(0,1){ }^{6}$

Turning to preferences, we assume an Epstein-Zin specification with constant elasticity of intertemporal substitution (CEIS) and constant relative risk aversion (CRRA). Given a consumption process, the utility process is defined by the solution to the following integral equation:

$$
U_{t}=E_{t} \int_{t}^{\infty} z\left(c_{s}, U_{s}\right) d s
$$

where

$$
z(c, U) \equiv \frac{\beta}{1-1 / \theta}\left[\frac{c^{1-1 / \theta}}{((1-\gamma) U)^{\frac{-1 / \theta+\gamma}{1-\gamma}}}-(1-\gamma) U\right]
$$

\footnotetext{
${ }^{6}$ The characterization of equilibrium and the proof of the existence of the steady state extend to any neoclassical production function; it is only the proof of the uniqueness of the steady state that uses the Cobb-Douglas specification.
} 
Here, $\beta>0$ is the discount rate, $\gamma>0$ is the coefficient of relative risk aversion, and $\theta>0$ is the elasticity of intertemporal substitution. ${ }^{7}$

Standard expected utility is nested with $\gamma=1 / \theta$. We find it useful to allow $\theta \neq 1 / \gamma$ in order to clarify that the qualitative properties of the steady state depend crucially on the elasticity of intertemporal substitution rather than the coefficient of relative risk aversion (which in turn also guides our preferred parameterizations of the model). However, none of our results rely on allowing $\theta \neq 1 / \gamma$. A reader who feels uncomfortable with the Epstein-Zin specification can therefore ignore it, assume instead standard expected utility, and simply replace $\gamma$ with $1 / \theta$ (or vice versa) in all the formulas that follow.

\subsection{Government}

At each point in time the government consumes output at the rate $G_{t}$. Government spending is deterministic, it is financed with lump-sum taxation, and it does not affect either utility from private consumption or production. The government budget constraint is given by

$$
d B_{t}^{g}=\left[R_{t} B_{t}^{g}+T_{t}-G_{t}\right] d t
$$

where $B_{t}^{g}$ denotes the level of government assets (i.e., minus the level of government debt). Finally, a no-Ponzi game condition is imposed to rule out explosive debt accumulation.

\subsection{Equilibrium definition}

The initial position of the economy is given by the distribution of $\left(k_{0}^{i}, b_{0}^{i}\right)$ across households. Households choose plans $\left\{c_{t}^{i}, n_{t}^{i}, k_{t}^{i}, b_{t}^{i}\right\}_{t \in[0, \infty)}$, contingent on the history of their idiosyncratic shocks, and given the price sequence and the government policy, so as to maximize their lifetime utility. Idiosyncratic risk, however, washes out in the aggregate. We thus define an equilibrium as a deterministic sequence of prices $\left\{\omega_{t}, R_{t}\right\}_{t \in[0, \infty)}$, a deterministic sequence of policies $\left\{G_{t}, T_{t}\right\}_{t \in[0, \infty)}$, a deterministic macroeconomic path $\left\{C_{t}, K_{t}, Y_{t}\right\}_{t \in[0, \infty)}$, and a collection of individual contingent plans $\left(\left\{c_{t}^{i}, n_{t}^{i}, k_{t}^{i}, b_{t}^{i}\right\}_{t \in[0, \infty)}\right)_{i \in[0,1]}$, such that the following conditions hold: (i) given the sequences of prices and policies, the plans are optimal for the households; (ii) the labor market clears, $\int_{t} n_{t}^{i}=1$, in all $t$; (iii) the bond market clears, $\int_{t} b_{t}^{i}+B_{t}^{g}=0$, in all $t$; (iv) the government budget is satisfied in all $t$; and (v) the aggregates are consistent with individual behavior, $C_{t}=\int_{i} c_{t}^{i}, K_{t}=\int_{i} k_{t}^{i}$, and $Y_{t}=\int_{i} F\left(k_{t}^{i}, n_{t}^{i}\right)$, in all $t .^{8}$

\footnotetext{
${ }^{7}$ To make sure that (4) indeed defines a preference ordering over consumption lotteries, one must establish existence and uniqueness of the solution to the integral equation (4); see Duffie and Epstein (1992).

${ }^{8}$ Throughout, $\int_{i}$ denotes expectation in the cross-section of the population.
} 


\section{Equilibrium}

In this section we characterize the equilibrium of the economy. We first solve for a household's optimal plan for given sequences of prices and policies. We then aggregate across households and derive the general-equilibrium dynamics.

\subsection{Individual behavior}

Since employment is chosen after the capital stock has been installed and the idiosyncratic shock has been observed, optimal employment maximizes profits state by state. By constant returns to scale, optimal firm employment and profits are linear in own capital:

$$
n_{t}^{i}=\bar{n}\left(\omega_{t}\right) k_{t}^{i} \quad \text { and } \quad d \pi_{t}^{i}=\bar{r}\left(\omega_{t}\right) k_{t}^{i} d t+\sigma d z_{t}^{i}
$$

where $\bar{n}\left(\omega_{t}\right) \equiv \arg \max _{n}\left[F(1, n)-\omega_{t} n\right]$ and $\bar{r}\left(\omega_{t}\right) \equiv \max _{n}\left[F(1, n)-\omega_{t} n\right]-\delta$. Here, $\bar{r}_{t} \equiv \bar{r}\left(\omega_{t}\right)$ is the household's expectation of the return to its capital prior to the realization of the idiosyncratic

shock $z_{t}^{i}$, as well as the mean of the realized returns in the cross-section of firms. Analogous interpretation applies to $\bar{n}_{t} \equiv \bar{n}\left(\omega_{t}\right)$.

The key result here is that households face risky, but linear, returns to their capital. To see how this translates to linearity of wealth in assets, let $h_{t}$ denote the present discounted value of future labor income net of taxes, a.k.a. human wealth:

$$
h_{t}=\int_{t}^{\infty} e^{-\int_{t}^{s} R_{j} d j}\left(\omega_{s}-T_{s}\right) d s
$$

Next, define effective wealth as the sum of financial and human wealth:

$$
w_{t}^{i} \equiv x_{t}^{i}+h_{t}=k_{t}^{i}+b_{t}^{i}+h_{t}
$$

It follows that the evolution of effective wealth can be described by

$$
d w_{t}^{i}=\left[\bar{r}_{t} k_{t}^{i}+R_{t}\left(b_{t}^{i}+h_{t}\right)-c_{t}^{i}\right] d t+\sigma k_{t}^{i} d z_{t}^{i}
$$

The first term on the right-hand side of (10) measures the expected rate of growth in the household's effective wealth; the second term captures the impact of idiosyncratic risk.

The linearity of budgets together with the homotheticity of preferences ensures that, for given prices and policies, the household's consumption-saving problem reduces to a tractable homothetic problem as in Samuelson's and Merton's classic portfolio analysis. It follows that the optimal policy rules are linear in wealth, as shown in the next proposition. 
Proposition 1. Let $\left\{\omega_{t}, R_{t}\right\}_{t \in[0, \infty)}$ and $\left\{G_{t}, T_{t}\right\}_{t \in[0, \infty)}$ be equilibrium price and policy sequences. Then, equilibrium consumption, investment and bond holdings for household $i$ are given by

$$
c_{t}^{i}=m_{t} w_{t}^{i}, \quad k_{t}^{i}=\phi_{t} w_{t}^{i}, \quad \text { and } \quad b_{t}^{i}=\left(1-\phi_{t}\right) w_{t}^{i}-h_{t},
$$

where $\phi_{t}$, the fraction of effective wealth invested in capital, is given by

$$
\phi_{t}=\frac{\bar{r}_{t}-R_{t}}{\gamma \sigma^{2}}
$$

while $m_{t}$, the marginal propensity to consume out of effective wealth, satisfies the recursion

$$
\frac{\dot{m}_{t}}{m_{t}}=m_{t}+(\theta-1) \hat{\rho}_{t}-\theta \beta
$$

with $\hat{\rho}_{t} \equiv \rho_{t}-\frac{1}{2} \gamma \phi_{t}^{2} \sigma^{2}$ denoting the risk-adjusted return to saving and $\rho_{t} \equiv \phi_{t} \bar{r}_{t}+\left(1-\phi_{t}\right) R_{t}$ the mean return to saving.

Condition (12) simply says that the fraction of wealth invested in the risky asset is increasing in the risk premium $\mu_{t} \equiv \bar{r}_{t}-R_{t}$, and decreasing in risk aversion $\gamma$ and the amount of risk $\sigma .{ }^{9}$ Condition (13) is essentially the Euler condition: it describes the growth rate of the marginal propensity to consume as a function of the anticipated path of risk-adjusted returns to saving. Whether higher risk-adjusted returns increase or reduce the marginal propensity to consume depends on the elasticity of intertemporal substitution. To see this more clearly, note that in steady state this condition reduces to $m=\theta \beta-(\theta-1) \hat{\rho}$, so that higher $\hat{\rho}$ decreases $m$ (i.e., increases saving out of effective wealth) if and only if $\theta>1$. This is due to the familiar income and substitution effects.

\subsection{General equilibrium}

Because individual consumption, saving and investment are linear in individual wealth, aggregates at any point in time do not depend on the extent of wealth inequality at that time. As a result, the aggregate equilibrium dynamics can be described with a low-dimensional recursive system.

Define $f(K) \equiv F(K, 1)$ as the production in intensive form and let $\omega(K) \equiv f(K)-f^{\prime}(K) K$, $\phi(K, R) \equiv \frac{1}{\gamma \sigma^{2}}\left(f^{\prime}(K)-\delta-R\right)$, and $\rho(K, R) \equiv R+\frac{1}{\gamma \sigma^{2}}\left(f^{\prime}(K)-\delta-R\right)^{2}$. Aggregating across the policy rules of the agents and imposing market clearing, we arrive at the following proposition.

\footnotetext{
${ }^{9}$ Clearly, in any equilibrium $\mu_{t}$ must be positive, otherwise nobody would invest in capital and an equilibrium would fail to exist.
} 
Proposition 2. In equilibrium, the aggregate dynamics satisfy

$$
\begin{gathered}
\dot{K}_{t}=f\left(K_{t}\right)-\delta K_{t}-C_{t}-G_{t} \\
\frac{\dot{C}_{t}}{C_{t}}=\theta\left(\rho_{t}-\beta\right)-(\theta-1) \frac{1}{2} \gamma \sigma^{2} \phi_{t}^{2} \\
\dot{H}_{t}=R_{t} H_{t}-\omega_{t}+G_{t} \\
K_{t}=\frac{\phi_{t}}{1-\phi_{t}} H_{t}
\end{gathered}
$$

with $\omega_{t}=\omega\left(K_{t}\right), \phi_{t}=\phi\left(K_{t}, R_{t}\right)$, and $\rho_{t}=\rho\left(K_{t}, R_{t}\right)$.

Condition (14) is the resource constraint of the economy. The resource constraint does not depend on the degree of market incompleteness. It follows from aggregating budgets across all households and the government, imposing labor- and bond-market clearing, and using the linearity of individual firm employment to individual capital together with constant returns to scale, to get $Y_{t}=\int_{i} F\left(k_{t}^{i}, n_{t}^{i}\right)=F\left(\int_{i} k_{t}^{i}, \int_{i} n_{t}^{i}\right)=F\left(K_{t}, 1\right)$.

Condition (15) is the aggregate Euler condition for the economy. It follows from aggregating consumption and wealth across agents together with the optimality condition (13) for the marginal propensity to consume. It also has a simple interpretation. As in the case of complete markets, aggregate consumption growth unambiguously increases with $\rho_{t}$, the mean return to saving. But unlike complete markets, aggregate consumption growth now also depends on $\frac{1}{2} \gamma \sigma^{2} \phi_{t}^{2}$, a riskadjustment term. Whether more risk contributes to a lower or higher marginal propensity to save, and hence whether this new term contributes to lower or higher consumption growth, depends on whether the elasticity of intertemporal substitution, $\theta$, is higher or lower than 1 . The intuition for this property is the same as the intuition for the impact of the interest rate in a deterministic saving problem, namely the opposing income and substitution effects of a higher rate of return to saving.

Condition (16) expresses the evolution of the present value of aggregate net-of-taxes labor income in recursive form. It follows from the definition of human wealth combined with the intertemporal government budget, which imposes that the present value of taxes equals the present value of government consumption.

Finally, condition (17) follows from bond-market clearing. More precisely, aggregating bond holdings across agents and imposing bond-market clearing gives $\left(1-\phi_{t}\right) W_{t}-H_{t}=0$, while aggregating investment gives $K_{t}=\phi_{t} W_{t}$, and combining the two gives condition (17).

These conditions characterize the equilibrium dynamics of the economy with either incomplete or complete markets. In both cases, condition (17) ensures that $\phi_{t} \in(0,1)$. But when markets are complete $(\sigma=0)$, this is possible only if $f^{\prime}\left(K_{t}\right)-\delta=R_{t}$ (meaning arbitrage between bonds and capital). Condition (15) then reduces to the more familiar Euler condition $\dot{C}_{t} / C_{t}=\theta\left[f^{\prime}\left(K_{t}\right)-\delta-\beta\right]$, 
and one can track the dynamics of the economy merely on the $(C, K)$ space, using the Euler condition and the resource constraint. When, instead, markets are incomplete, $\phi_{t} \in(0,1)$ is possible only if $f^{\prime}\left(K_{t}\right)-\delta>R_{t}$, which proves that the marginal product of capital must exceed the risk-free rate. Moreover, the dimensionality of the system now increases by one: along with $(C, K)$, we also have to keep track of $H$, using condition (16).

Still, this is a highly tractable dynamic system, as compared to other incomplete-markets models, where the entire wealth distribution - an infinite dimensional object - is a relevant state variable for aggregate equilibrium dynamics. Indeed, the equilibrium dynamics can be approximated with a simple shooting algorithm: for any historically given $K_{0}$, guess some initial values $\left(C_{0}, H_{0}\right)$ and use conditions (14)-(16) to compute the entire path of $\left(C_{t}, K_{t}, H_{t}\right)$ for $t \in[0, T]$, for some large $T$; then iterate on the initial guess till $\left(C_{T}, K_{T}, H_{T}\right)$ is close enough to its steady-state value. ${ }^{10}$ In the special case that $\theta=1$ (unit EIS), $m_{t}=\beta$ and hence $C_{t}=\beta\left(K_{t}+H_{t}\right.$ ) for all $t$. One can then drop the Euler condition from the dynamic system and analyze the equilibrium dynamics with a simple phase diagram in the $(K, H)$ space.

\section{Steady State}

In this section we study the steady state of the economy (i.e., the fixed point of the dynamic system in Proposition 2) and its comparative statics with respect to the level of government spending.

\subsection{Characterization}

Clearly, an equilibrium would fail to exist if the present value of government spending exceeded that of labor income. We thus henceforth parameterize government spending $G_{t}$ as a fraction $g$ of aggregate output $Y_{t}$ and impose $0 \leq g<1-\alpha$.

Proposition 3. (i) The steady state exists and is unique. (ii) In steady state, the capital stock $K$ and the interest rate $R$ are the unique solution to

$$
\begin{aligned}
& f^{\prime}(K)-\delta=R+\sqrt{\frac{2 \theta \gamma \sigma^{2}(\beta-R)}{\theta+1}} \\
& K=\frac{\phi(K, R)}{1-\phi(K, R)} \frac{(1-\alpha-g) f(K)}{R}
\end{aligned}
$$

Output is then given by $Y=f(K)$, the wage rate by $\omega=(1-\alpha) f(K)$, and consumption by $C=(1-g) f(K)-\delta K$.

\footnotetext{
${ }^{10}$ This presumes that a turnpike theorem applies; this is likely to be the case at least for $\sigma$ small enough, by continuity to the complete-markets case.
} 
Condition (18) follows from the Euler condition (15), setting $\dot{C}=0$. Condition (19) follows from the bond market clearing condition (17), substituting for the steady-state value of $H$ implied by (16), namely $H=(\omega-G) / R=(1-\alpha-g) f(K) / R$.

To better understand the determination of the steady state of our economy, consider for a moment another economy that has the same preferences, technologies and risks but is open to an international market for the riskless bond, thus facing an exogenously fixed interest rate. If $R \geq 1 / \beta$, then the precautionary saving motive implies that aggregate wealth increases without bound. If, instead, $R \in(0,1 / \beta)$, then diminishing absolute aversion ensures the existence of a finite level of aggregate wealth at which the precautionary motive is just offset by the gap between the interest rate and the discount rate. ${ }^{11}$ Therefore, $R \in(0,1 / \beta)$ is both necessary and sufficient for the open economy to admit a steady state. For any such $R$, aggregate capital is given by (18). There is, however, a unique $R$ for which the net foreign asset position of the economy is zero, which is precisely what condition (19) imposes.

\subsection{A graphical representation}

Let $K_{1}(R)$ and $K_{2}(R ; g)$ denote the solutions to, respectively, conditions (18) and (19) with respect to $K$. For any given $g$, the intersection of the graphs of these two functions identifies the steady state. To understand how these graphs look like, the next lemma examines the monotonicities of these two functions with respect to $R$.

Lemma 1. (i) $\partial K_{1} / \partial R>0$ if and only if $\theta>\frac{\phi}{1-\phi}$. (ii) $\partial K_{2} / \partial R<0$ always.

The intuition behind part (ii) is simple. For given $K$, and hence given $\omega$, an increase in $R$ reduces both $H$ and $\phi(K, R)$, and thereby necessarily reduces the right hand side of (19). But then for (19) to hold with the lower $R$ it must be that $K$ also falls. It follows that $K_{2}(R)$ is a monotonically decreasing function, as illustrated in Figure 1.

The intuition behind part (i) is a bit more convoluted. Recall that condition (18) comes from stationarity of aggregate consumption. Clearly, this is equivalent to imposing stationarity of aggregate wealth. Since $\dot{W}_{t}=\rho_{t} W_{t}-C_{t}=\left(\rho_{t}-m_{t}\right) W_{t}$, this in turn is the same as imposing $\rho=m$. From condition (13), on the other hand, we have that the steady-state value of the marginal propensity to consume is given by $m=\theta \beta-(\theta-1) \hat{\rho}$. It follows that aggregate wealth is stationary if and only if

$$
\rho+(\theta-1) \hat{\rho}=\theta \beta
$$

where $\rho$ is the mean return to saving and $\hat{\rho}$ the risk adjusted return (both evaluated at the steady state $K$ and for given $R$ ). Of course, this condition is equivalent to (18), but it is more useful for developing intuition.

\footnotetext{
${ }^{11}$ These intuitions are similar to those in Aiyagari (1994).
} 


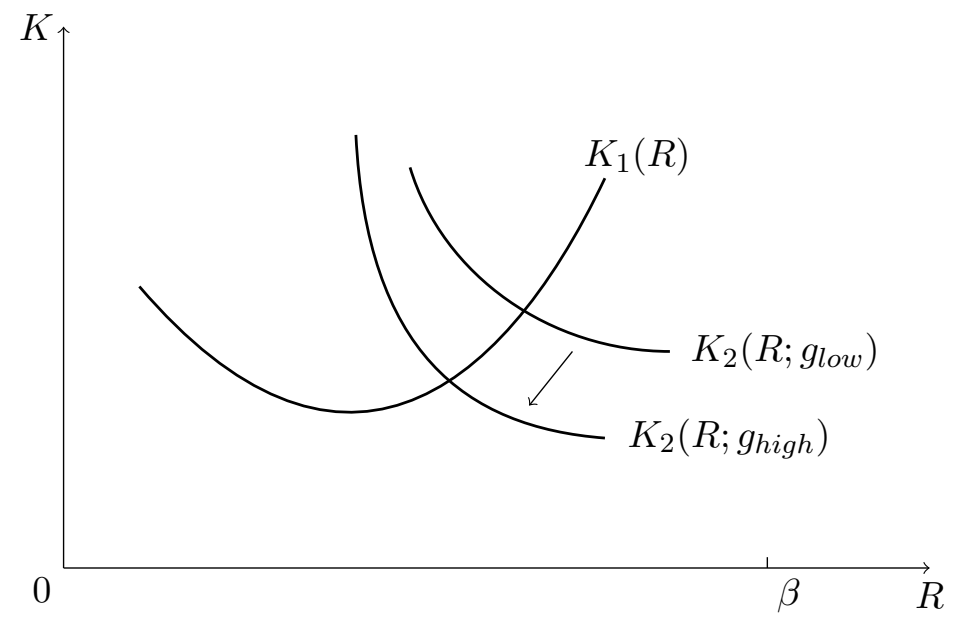

Figure 1. The steady state and the effects of higher government spending.

First, note that an increase in $K$ necessarily reduces $\rho+(\theta-1) \hat{\rho}$. To see this, note that an increase in $K$ reduces $f^{\prime}(K)$. For given $\phi$, this reduces $\rho$ and $\hat{\rho}$ equally, thus also reducing $\rho+(\theta-1) \hat{\rho}$. Of course, the optimal $\phi$ must fall, but this only reinforces the negative effect on $\rho$ (since the portfolio is shifted towards the low-return bond), while it does not affect $\hat{\rho}$ (because of the envelope theorem and the fact that $\phi$ maximizes $\hat{\rho}$ ).

Next, note that an increase in $R$ has an ambiguous effect on $\rho+(\theta-1) \hat{\rho}$. For given $\phi$, both $\rho$ and $\hat{\rho}$ increase with $R$. But now the fact that $\phi$ falls works in the opposite direction, contributing to lower $\rho$. Intuitively, though, this effect should be small if $\phi$ was small to start with. Moreover, the impact of $\hat{\rho}$ is likely to dominate if $\theta$ is high. We thus expect $\rho+(\theta-1) \hat{\rho}$ to increase with $R$ if and only if either $\phi$ is low or $\theta$ is high. Indeed, we prove that this is the case if and only if $\theta>\frac{\phi}{1-\phi}$.

Combining the above observations, we conclude that $\partial K_{1} / \partial R>0$ if and only if $\theta>\frac{\phi}{1-\phi}$, which completes the argument behind part (i) of Lemma 1.

In the Appendix, we further show that the steady-state $\phi$ is a decreasing function of $R$. Hence, the condition $\theta>\frac{\phi}{1-\phi}$ is satisfied if and only if $R$ is high enough. It follows that $K_{1}(R)$ is a U-shaped curve, as illustrated in Figure 1. Intuitively, when $R$ is close to $\beta$, a marginal increase in $R$ has such a strong positive effect on steady state wealth, that the consequent reduction in the risk premium more than offsets the increase in the opportunity cost of investment, ensuring that $K$ increases with $R$.

As noted earlier, the intersection of the two curves identifies the steady state of the closed economy. The existence and uniqueness of such an intersection is established in the Appendix (see the proof of Proposition 3). What we next seek to understand is how this intersection changes with an increase in government spending. 


\subsection{The long-run effects of government consumption}

Because $g$ does not enter condition (18), an increase in government consumption does not affect the $K_{1}$ curve. On the other hand, because higher $g$ means lower net-of-taxes labor income, and hence lower $H$, an increase in government consumption causes the $K_{2}$ curve to shift downwards, as illustrated in Figure 1. This is simply a manifestation of the negative wealth effect of higher lump-sum taxes. Clearly, $R$ unambiguously falls, whereas the impact on $K$ depends on whether the two curves intersect in the upward or the downward portion of the $K_{1}$ curve. From part (i) of Lemma 1 we know that the intersection occurs in the upward portion if and only if $\theta>\frac{\phi}{1-\phi}$. The main result of the paper is then immediate.

Proposition 4. In steady state, higher government consumption $(g)$ necessarily decreases the riskfree rate $(R)$, while it also decreases the capital-labor ratio $(K / N)$, labor productivity $(Y / N)$, the wage rate $(\omega)$, and the saving rate $(s \equiv \delta K / Y)$ if and only if

$$
\theta>\frac{\phi}{1-\phi}
$$

With complete markets, the steady state interest rate is equated to the discount rate $(R=\beta)$, and the steady state capital-labor ratio is determined by the equality of the marginal product of capital to the discount rate $\left(f^{\prime}(K / N)-\delta=\beta\right)$. It follows that, in the long run, government consumption has no effect on either $R$ or $K / N, Y / N, \omega$, and $s .{ }^{12}$

Here, instead, government consumption can have non-trivial long-run effects, even if financed with lump-sum taxation. Because households face consumption risk, they have a precautionary motive to save. Because preferences exhibit diminishing absolute risk aversion, this motive is stronger when the level of wealth is lower. It follows that, by reducing household wealth, higher government spending stimulates precautionary saving. But then the risk-free rate at which aggregate saving can be stationary has to be lower, which proves that $R$ falls with $g .{ }^{13}$

The impact of this fall in $R$ on the capital-labor ratio now depends on two opposing effects. On the one hand, because of diminishing absolute risk aversion, a lower level of wealth implies a lower willingness to take risk, which tends to discourage investment. On the other hand, a lower risk-free rate implies a lower opportunity cost of investment, which tends to stimulate investment. As explained earlier, the wealth effect dominates when $\theta>\frac{\phi}{1-\phi} \cdot{ }^{14}$ Since $\phi<\alpha$, this is the case as long as the elasticity of intertemporal substitution is high relative to the income share of capital.

\footnotetext{
${ }^{12}$ This result is true even when labor supply is endogenous (as in Section 5). The only difference is that in the latter case, while $K / N$ and $Y / N$ continue to not change, $N$ changes and hence $K$ and $Y$ also change.

${ }^{13}$ A similar intuition underlies the steady-state supply of saving in Aiyagari (1994).

${ }^{14}$ In the Appendix we prove that the steady-state $\phi$ is a decreasing function of the stead-state $R$, and hence an increasing function of $g$. It follows that, whenever the steady-state $K$ is a non-monotonic function of $g$, it is a $U$-shaped function of $g$. Note, however, that a high enough $\theta$ may suffice for $\theta$ to be higher than $\phi /(1-\phi)$ for all feasible levels of $g$, and hence for $K$ to be a globally decreasing function of $g$.
} 
For empirically plausible calibrations of the model, the condition $\theta>\frac{\phi}{1-\phi}$ is easily satisfied. For example, take the interest rate to be $R=4 \%$ and labor income to be $65 \%$ of GDP. Then $H$ is about 16 times GDP, or equivalently 4 times $K$, if we assume a capital-output ratio of 4 . Since in steady

state $\frac{\phi}{1-\phi}=\frac{K}{H}$, this exercise gives a calibrated value for $\frac{\phi}{1-\phi}$ about 0.25 . This is far lower than most of the recent empirical estimates of the elasticity of intertemporal substitution, which are typically around 1 if not higher. ${ }^{15}$ It follows that a negative long-run effect of government consumption on aggregate saving and productivity appears to be the most likely scenario.

\subsection{Numerical simulation}

We now numerically simulate the steady state of our economy, to get a first pass at the potential quantitative importance of our results.

The economy is fully parameterized by $(\alpha, \beta, \gamma, \delta, \theta, \sigma, g)$, where $\alpha$ is the income share of capital, $\beta$ is the discount factor, $\gamma$ is the coefficient of relative risk aversion, $\delta$ is the (mean) depreciation rate, $\theta$ is the elasticity of intertemporal substitution, $\sigma$ is the standard deviation of the rate of return on private investment, and $g$ is the share of government consumption in aggregate output.

In our baseline parametrization, we take $\alpha=0.36, \beta=0.96$, and $\delta=0.08$; these values are standard in the literature. For risk aversion, we take $\gamma=5$, a value commonly used in the macro-finance literature to help generate plausible risk premia. For the elasticity of intertemporal substitution, we take $\theta=1$, a value consistent with recent micro and macro estimates. ${ }^{16}$ For the share of government, our baseline value is $g=25 \%$ (as in the United States) and a higher alternative is $g=40 \%$ (as in some European countries).

What remains is $\sigma$. Unfortunately, there is no direct measure of the rate-of-return risk faced by the "typical" investor in the US economy. However, there are various indications that investment risks are significant. For instance, the probability that a privately held firm survives five years after entry is less than $40 \%$. Furthermore, even conditional on survival, the risks faced by entrepreneurs and private investors appear to be very large: as Moskowitz and Vissing-Jørgensen (2002) document, not only there is a dramatic cross-sectional variation in the returns to private equity, but also the volatility of the book value of a (value-weighted) index of private firms is twice as large as that of the index of public firms - one more indication that private equity is more risky than public equity. Note then that the standard deviation of annual returns is about $15 \%$ per annum for the entire pool of public firms; it is over $50 \%$ for a single public firm (which gives a measure of firm-specific risk); and it is about $40 \%$ for a portfolio of the smallest public firms (which are likely to be similar to large private firms).

\footnotetext{
${ }^{15}$ See, for example, Vissing-Jørgensen and Attanasio (2003), Mulligan (2002), and Gruber (2005). See also Guvenen (2006) and Angeletos (2007) for related discussions on the parametrization of the EIS.

${ }^{16}$ See the references in footnote 15.
} 
Given this suggestive evidence, and in want of a better alternative, we take $\sigma=30 \%$ for our baseline parameterization and consider $\sigma=20 \%$ and $\sigma=40 \%$ for sensitivity analysis. Although these numbers are somewhat arbitrary, the following observation is reassuring: the volatility of individual consumption generated by our model is comparable to its empirical counterpart. For instance, using the Consumer Expenditure Survey (CEX), Malloy, Moskowitz and Vissing-Jørgensen (2006) estimate the standard deviation of consumption growth to be about $8 \%$ for stockholders (and about 3\% for non-stockholders). Similarly, using data that include consumption of luxury goods, Aït-Sahalia, Parker and Yogo (2001) get estimates between $6 \%$ and 15\%. In our simulations, on the other hand, the standard deviation of individual consumption growth is less than $5 \%$ per annum (along the steady state).

Putting aside these qualifications about the parametrization of $\sigma$, we now examine the quantitative effects of government consumption on the steady state of the economy. Table 1 reports the per-cent reduction in the steady-state values of the capital-labor ratio $(K / N)$, labor productivity $(Y / N)$, and the saving rate $(s)$, relative to what their values would have been if $g$ were $0 .{ }^{17}$ Complete markets are indicated by CM and incomplete markets by IM.

\begin{tabular}{|c||c|c||c|c||c|c||c|}
\hline \multicolumn{1}{|c||}{} & \multicolumn{2}{c||}{$K / N$} & \multicolumn{2}{c||}{$Y / N$} & \multicolumn{2}{c||}{$s$} & $\tau_{\text {equiv }}^{k}$ \\
\cline { 2 - 8 } & CM & IM & CM & IM & CM & IM & CM \\
\hline baseline & $\mathbf{0}$ & $\mathbf{- 1 0 . 0 2}$ & $\mathbf{0}$ & $\mathbf{- 3 . 7 3}$ & $\mathbf{0}$ & $\mathbf{- 1 . 1 4}$ & $\mathbf{1 7}$ \\
\hline$\sigma=40 \%$ & 0 & -12.18 & 0 & -4.57 & 0 & -1.21 & 20 \\
\hline$\sigma=20 \%$ & 0 & -6.78 & 0 & -2.5 & 0 & -0.88 & 12 \\
\hline$g=40 \%$ & 0 & -17.82 & 0 & -6.82 & 0 & -2.05 & 28 \\
\hline
\end{tabular}

Table 1. The steady-state effects of the size of government.

In our baseline parametrization, the capital-labor ratio is about $10 \%$ lower when $g=25 \%$ than when $g=0$. Similarly, productivity is about $4 \%$ lower and the saving rate is about 1 percentage point lower. These are significant effects. They are larger (in absolute value) than the steady-state effects of precautionary saving reported in Aiyagari (1994). They are equivalent to what would be the steady-state effects of a marginal tax on capital income equal to $17 \%$ in the complete-markets case. (The tax rate on capital income that would generate the same effects under complete markets is given in the last column of the table, as $\tau_{\text {equiv }}^{k}$.)

Not surprisingly, the effects are smaller if $\sigma$ is lower (third row) or if $\gamma$ is lower (not reported), because then risk matters less. On the other hand, the effects are larger when $g=40 \%$ (final row): productivity is almost $18 \%$ lower, the saving rate is 2 percentage points lower, and the tax on capital income that would have generated the same effects under complete markets is $28 \%$.

\footnotetext{
${ }^{17}$ Here, since labor supply is exogenously fixed, the changes in $K$ and $Y$ coincide with those in $K / N$ and $Y / N$; this is not the case in the extensions with endogenous labor supply in the next section.
} 
Table 2 turns from level to marginal effects: it reports the change in $K / N, Y / N$, and $s$ as we increase government spending by 1 percent, either from $25 \%$ to $26 \%$, or from $40 \%$ to $41 \%$. In the first case, productivity falls by $0.19 \%$; in the second, by $0.26 \%$. This is equivalent to what would have been under complete markets the effect of increasing the tax rate on capital income by about 0.75 percentage points in the first case, and about 0.8 percentage points in the second case.

\begin{tabular}{|c||c|c||c|c||c|}
\hline \multicolumn{1}{|c||}{} & \multicolumn{2}{c||}{$K / N$} & \multicolumn{2}{c||}{$Y / N$} & $\tau_{\text {equiv }}^{k}$ \\
\cline { 2 - 6 } & $\mathrm{CM}$ & $\mathrm{IM}$ & $\mathrm{CM}$ & $\mathrm{IM}$ & $\mathrm{CM}$ \\
\hline$g=25 \% \rightarrow 26 \%$ & 0 & -0.52 & 0 & -0.19 & 0.75 \\
\hline$g=40 \% \rightarrow 41 \%$ & 0 & -0.71 & 0 & -0.26 & 0.8 \\
\hline
\end{tabular}

Table 2. Long-run effects of a permanent $1 \%$ increase in government consumption.

\section{Endogenous labor}

In this section we endogenize labor supply in the economy. We consider three alternative specifications that achieve this goal without compromising the tractability of the model.

\subsection{GHH preferences}

One easy way to accommodate endogenous labor supply in the model is to assume preferences that rule out income effects on labor supply, as in Greenwood, Hercowitz and Huffman (1998). In particular, suppose that preferences are given by $U_{0}=\mathbb{E}_{0} \int_{0}^{\infty} e^{-\beta t} u\left(c_{t}, l_{t}\right) d t$, with

$$
u\left(c_{t}, l_{t}\right)=\frac{1}{1-\gamma}\left[c_{t}+v\left(l_{t}\right)\right]^{1-\gamma}
$$

where $l_{t}$ denotes leisure and $v$ is a strictly concave, strictly increasing function. ${ }^{18}$ The analysis can then proceed as in the benchmark model, with labor supply in period $t$ given by $N_{t}=1-l\left(\omega_{t}\right)$, where $l(\omega) \equiv \arg \max _{l}\{v(l)-\omega l\}$.

This specification highlights an important difference between complete and incomplete markets with regard to the employment impact of fiscal shocks. Under incomplete markets, an increase in government spending can have a negative general-equilibrium effect on aggregate employment. This is never possible with complete markets, but it is possible with incomplete markets when an increase in $g$ reduces the capital-labor ratio, and thereby the wage rate, which in turn discourages labor supply. Indeed, with GHH preferences, $\theta>\frac{\phi}{1-\phi}$ suffices for both $K / N$ and $N$ to fall with $g$ in both the short run and the long run.

\footnotetext{
${ }^{18}$ To allow for $\theta \neq 1 / \gamma$, we let $U_{t}=\mathbb{E}_{t} \int_{t}^{\infty} z\left(c_{\tau}+v\left(l_{\tau}\right), U_{\tau}\right) d \tau$, with the function $z$ defined as in condition (5).
} 
Although it is unlikely that wealth effects on labor supply are zero in the long run, they may well be very weak in the short run. In the light of our results, one may then expect that after a positive shock to government consumption both employment and investment could drop on impact under incomplete markets. ${ }^{19}$

\section{$5.2 \quad$ KPR preferences}

A second tractable way to accommodate endogenous labor supply is to assume that agents have homothetic preferences over consumption and leisure, as in King, Plosser, and Rebelo (1988). In particular, suppose that preferences are given by $U_{0}=\mathbb{E}_{0} \int e^{-\beta t} u\left(c_{t}, l_{t}\right) d t$, with

$$
u\left(c_{t}, l_{t}\right)=\frac{1}{1-\gamma}\left[c_{t}^{1-\psi} l_{t}^{\psi}\right]^{1-\gamma}
$$

where $l_{t}$ denotes leisure and $\psi \in(0,1)$ is a scalar. ${ }^{20}$

The benefit of this specification is that it is standard in the literature (making our results comparable to previously reported results), while it also comes with zero cost in tractability once augmented with the assumption that agents can trade leisure with one another. ${ }^{21}$ The homotheticity of the household's optimization problem is then preserved and the equilibrium analysis proceeds in a similar fashion as in the benchmark model. ${ }^{22}$ The only essential novelty is that aggregate employment is now given by $N_{t}=1-L\left(\omega_{t}, C_{t}\right)$, where

$$
L\left(\omega_{t}, C_{t}\right)=\frac{\psi}{1-\psi} \frac{C_{t}}{\omega_{t}}
$$

The neoclassical effect of wealth on labor supply is now captured by the negative relationship between $N_{t}$ and $C_{t}$ (for given $\omega_{t}$ ).

For the quantitative version of this economy, in line with King, Plosser, and Rebelo (1988) and Christiano and Eichenbaum (1992), we take $\psi=0.75$. This value ensures that the steady-state fraction of available time worked approximately matches the US data. The rest of the parameters are as in the baseline specification of the benchmark model.

\subsection{Hand-to-mouth workers}

A third approach is to split the population into two groups. The first group consists of the households that have been modeled in the benchmark model; we will call this group the "investors".

\footnotetext{
${ }^{19}$ This discussion indicates that an interesting extension might be to consider a preference specification that allows for weak short-run but strong long-run wealth effects, as in Jaimovich and Rebelo (2006).

${ }^{20}$ To allow for $\theta \neq 1 / \gamma$, we let $U_{t}=\mathbb{E}_{t} \int_{t}^{\infty} z\left(c_{\tau}^{\psi} l_{\tau}^{1-\psi}, U_{\tau}\right) d \tau$, with $z$ defined as in (5).

${ }^{21}$ Clearly, this last assumption is for modeling convenience: it allows individual leisure to increase proportionally with individual wealth.

${ }^{22}$ The proofs are available upon request.
} 
The second group consists of households that supply labor but do not hold any assets, and simply consume their entire labor income at each point in time; we will call this group the "hand-to-mouth workers". Their labor supply is given by

$$
N_{t}^{h t m}=\omega_{t}^{\epsilon_{\omega}}\left(C_{t}^{h t m}\right)^{\epsilon_{c}},
$$

where $C_{t}^{h t m}$ denotes the consumption of these agents, $\epsilon_{\omega}>0$ parameterizes the wage elasticity of labor supply, and $\epsilon_{c}>0$ parameterizes the wealth elasticity. ${ }^{23}$

This approach could be justified on its own merit. In the United States, a significant fraction of the population holds no assets, has limited ability to borrow, and sees its consumption tracking its income almost one-to-one. This fact calls for a richer model of heterogeneity than our benchmark model. But is unclear what the "right" model for these households is. Our specification with hand-to-mouth workers is a crude way of capturing this form of heterogeneity in the model while preserving its tractability.

A side benefit of this approach is that it also gives freedom in parameterizing the wage and wealth elasticities of labor supply. Whereas the KPR preference specification imposes $\epsilon_{\omega}=-\epsilon_{c}=1$, the specification introduced above permits us to pick much lower elasticities, consistent with micro evidence. The point is not to argue which parametrization of the labor-supply elasticities is more appropriate for quantitative exercises within the neoclassical growth model; this is the subject of a long debate in the literature, to which we have nothing to add. The point here is rather to cover a broader spectrum of empirically plausible quantitative results.

For the quantitative version of this economy, we thus take $\epsilon_{\omega}=0.25$ and $\epsilon_{c}=-0.25$, which are in the middle of most micro estimates. ${ }^{24}$ What then remains is the fraction of aggregate income absorbed by hand-to-mouth workers. As mentioned above, a significant fraction of the US population holds no assets. For example, using data from both the PSID and the SCF, Guvenen (2006) reports that the lower $80 \%$ of the wealth distribution owns only $12 \%$ of aggregate wealth and accounts for about $70 \%$ of aggregate consumption. Since some households may be able to smooth consumption even when their net worth is zero, $70 \%$ is likely to be an upper bound for the fraction of aggregate consumption accounted for by hand-to-mouth agents. We thus opt to calibrate the economy so that hand-to-mouth agents account for $50 \%$ of aggregate consumption. This is also the value of the relevant parameter that one would estimate if the model were to match US aggregate consumption data - we can deduce this from Campbell and Mankiw (1989). ${ }^{25}$

\footnotetext{
${ }^{23}$ Preferences that give rise to this labor supply are $u_{t}=c_{t}^{\zeta_{c}}-n_{t}^{\zeta_{n}}$, for appropriate $\zeta_{c}, \zeta_{n}$.

${ }^{24}$ See, for example, Hausman (1981), MaCurdy (1981), and Blundell and MaCurdy (1999).

${ }^{25}$ Note that the specification of aggregate consumption considered in Campbell and Mankiw coincides with the one implied by our model. Therefore, if one were to run their regression on data generated by our model, one would correctly identify the fraction of aggregate consumption accounted for by hand-to-mouth workers in our model. This implies that it is indeed appropriate to calibrate our model's relevant parameter to Campbell and Mankiw's estimate.
} 


\subsection{The long-run effects of government consumption with endogenous labor}

Our main theoretical result (Proposition 4) continues to hold in all of the above variants of the benchmark model: in steady state, a higher rate $g$ of government consumption necessarily reduces the interest rate $R$; and it also reduces the capital-labor ratio $K / N$, labor productivity $Y / N$, and the wage rate $\omega$ if and only if the elasticity of intertemporal substitution $\theta$ is higher than $\frac{\phi}{1-\phi} \cdot{ }^{26}$

What is not clear anymore is the effect of $g$ on $K$ and $Y$, because now $N$ is not fixed. On the one hand, the reduction in wealth stimulates labor supply, thus contributing to an increase in $N$. This is the familiar neoclassical effect of government spending on labor supply. On the other hand, as long as $\theta>\frac{\phi}{1-\phi}$, the reduction in capital intensity depresses real wages, contributing towards a reduction in $N$. This is the novel general-equilibrium effect due to incomplete markets. The overall effect of government spending on aggregate employment is therefore ambiguous under incomplete markets, whereas it is unambiguously positive under complete markets.

Other things equal, we expect the negative general-equilibrium effect to dominate, thus leading to a reduction in long-run employment after a permanent increase in government spending, if the wage elasticity of labor supply is sufficiently high relative to its income elasticity. This is clear in the GHH specification, where the wealth effect is zero. It can also be verified for the case of hand-to-mouth workers, where we have freedom in choosing these elasticities, but not in the case of KPR preferences, where both elasticities are restricted to equal one.

Given these theoretical ambiguities, we now seek to get a sense of empirically plausible quantitative effects. As already discussed, the GHH case (zero wealth effects on labor supply) is merely of pedagogical value. We thus focus on the parameterized versions of the other two cases, the economy with KPR (homothetic) preferences and the economy with hand-to-mouth workers.

Table 3 then presents the marginal effects on the steady-state levels of the capital-labor ratio, productivity, employment, and output for each of these two economies, as $g$ increases from $25 \%$ to $26 \%$, or from $40 \%$ to $41 \% .{ }^{27}$ The case of KPR preferences is indicated by KPR, while the case with hand-to-mouth workers is indicated by HTM. In either case, complete markets are indicated by $\mathrm{CM}$ and incomplete markets by IM.

Regardless of specification, the marginal effects of higher government spending on capital intensity $K / N$ and labor productivity $Y / N$ are negative under incomplete markets (and are stronger the higher is $g$ ), whereas they are zero under complete markets. As for aggregate employment $N$, the wealth effect of higher $g$ turns out to dominate the effect of lower wages under incomplete markets, so that $N$ increases with higher $g$ under either complete or incomplete markets. However, the employment stimulus is weaker under incomplete markets, especially in the economy with hand-

\footnotetext{
${ }^{26}$ This is true as long as the steady state is unique, which seems to be the case but has not been proved as in the benchmark model. Also, in the variant with hand-to-mouth agents, we have to be cautious to interpret $\phi$ as the ratio of private equity to effective wealth for the investor population alone.

${ }^{27}$ We henceforth focus on marginal rather than level effects just to economize on space.
} 


\begin{tabular}{|c|c|c|c|c|c|c|c|c|c|c|}
\hline & & \multicolumn{2}{|c|}{$K / N$} & \multicolumn{2}{|c|}{$Y / N$} & \multicolumn{2}{|c|}{$N$} & \multicolumn{2}{|c|}{$Y$} & $\tau_{\text {equiv }}^{k}$ \\
\hline & & $\mathrm{CM}$ & $\mathrm{IM}$ & $\overline{\mathrm{CM}}$ & IM & $\mathrm{CM}$ & $\mathrm{IM}$ & $\mathrm{CM}$ & IM & $\mathrm{CM}$ \\
\hline \multirow[t]{2}{*}{$g=25 \% \rightarrow 26 \%$} & KPR & 0 & -0.33 & 0 & -0.12 & 1.4 & 1.27 & 1.4 & 1.15 & 0.52 \\
\hline & HTM & 0 & -0.3 & 0 & -0.11 & 0.38 & 0.38 & 0.38 & 0.27 & 0.46 \\
\hline \multirow[t]{2}{*}{$g=40 \% \rightarrow 41 \%$} & KPR & 0 & -0.52 & 0 & -0.19 & 1.76 & 1.53 & 1.76 & 1.34 & 0.68 \\
\hline & HTM & 0 & -0.36 & 0 & -0.13 & 0.57 & 0.57 & 0.57 & 0.44 & 0.48 \\
\hline
\end{tabular}

Table 3. Long-run effects with endogenous labor.

to-mouth workers. The same is true for aggregate output: it increases under either incomplete or complete markets, but less so under incomplete markets. Finally, the incomplete-markets effects are on average equivalent to what would have been the effect of increasing the tax rate on capital income by about $0.55 \%$ under complete markets.

\section{Dynamic responses}

The results so far indicate that the long-run effects of government consumption can be significantly affected by incomplete risk sharing. We now examine how incomplete risk sharing affects the entire impulse response of the economy to a fiscal shock. ${ }^{28}$

Starting from the steady state with $g=25 \%$, we hit the economy with a permanent $1 \%$ increase in government spending. We then trace its transition to the new steady state (the one corresponding to $g=26 \%$ ). We conduct this experiment for both the economy with KPR (homothetic) preferences and the economy with hand-to-mouth workers, each parameterized as in the previous section; in either case, the transitional dynamics reduce to a simple system of two first-order ODE's in $\left(K_{t}, H_{t}\right)$ when $\theta=1 .^{29}$

The results are presented in Figures 2 and 3. Time in years is on the horizontal axis, while deviations of the macro variables from their respective initial values are on the vertical axis. The interest rate and the investment rate are in simple differences, the rest of the variables are in log differences. The solid lines indicate incomplete markets, the dashed lines indicate complete markets.

As evident in these figures, the quantitative effects of a permanent fiscal shock can be quite different between complete and incomplete markets. The overall picture that emerges is that the

\footnotetext{
${ }^{28}$ Note that the purpose of the quantitative exercises conducted here, and throughout the paper, is not to assess the ability of the model to match the data. Rather, the purpose is to detect the potential quantitative significance of the particular deviation we took from the standard neoclassical growth model.

${ }^{29}$ Throughout, we focus on permanent shocks. Clearly, transitory shocks have no impact in the long run. As for their short-run impact, the difference between complete and incomplete markets is much smaller than in the case of permanent shocks. This is simply because transitory shocks have very weak wealth effects on investment as long as agents can freely borrow and lend over time, which is the case in our model. However, we expect the difference between complete and incomplete markets to be larger once borrowing constraints are added to the model, for then investment will be sensitive to changes in current disposable income even if there is no change in present-value wealth.
} 


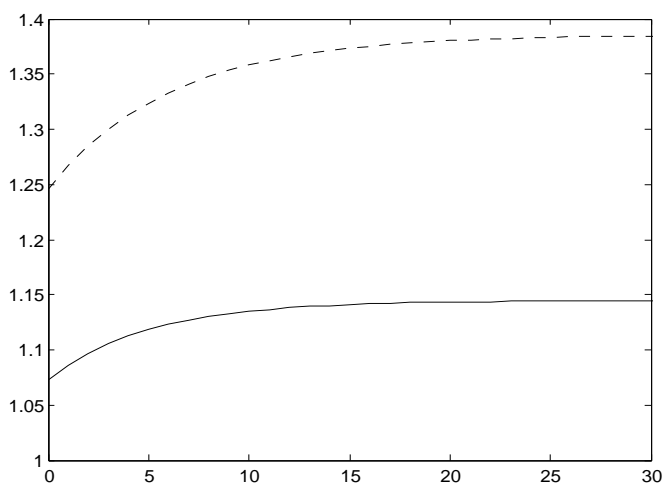

(a) Aggregate Output $Y_{t}$

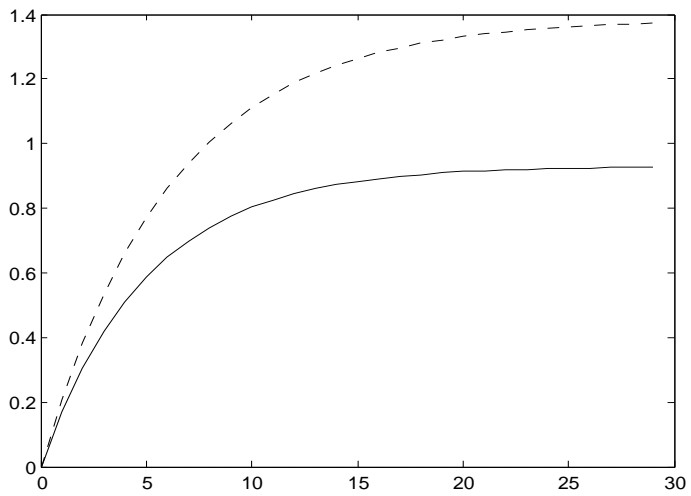

(c) Capital-Labor Ratio $K_{t} / N_{t}$

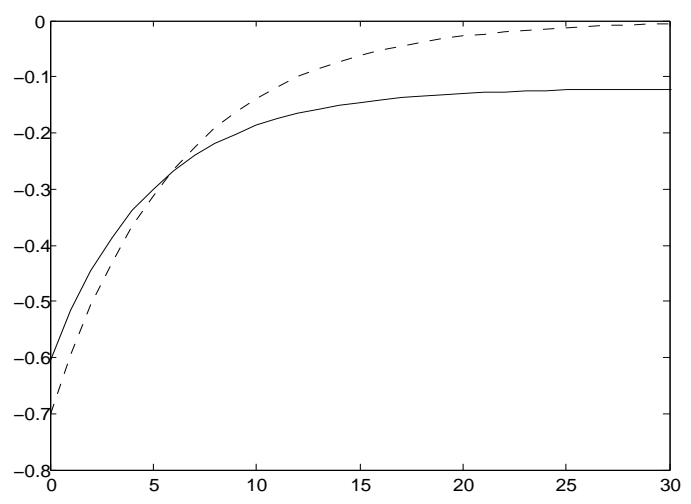

(e) Labor Productivity $Y_{t} / N_{t}$

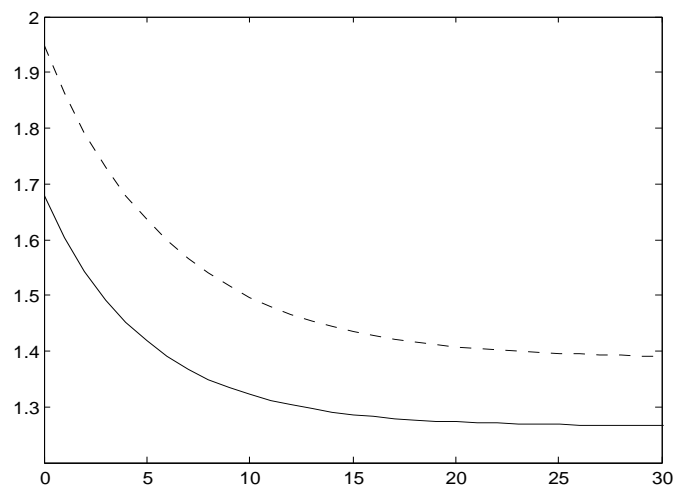

(b) Aggregate Employment $N_{t}$

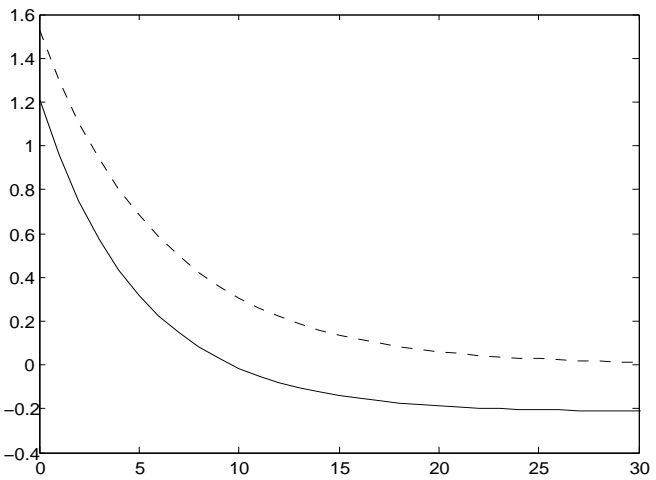

(d) Investment Rate $I_{t} / Y_{t}$

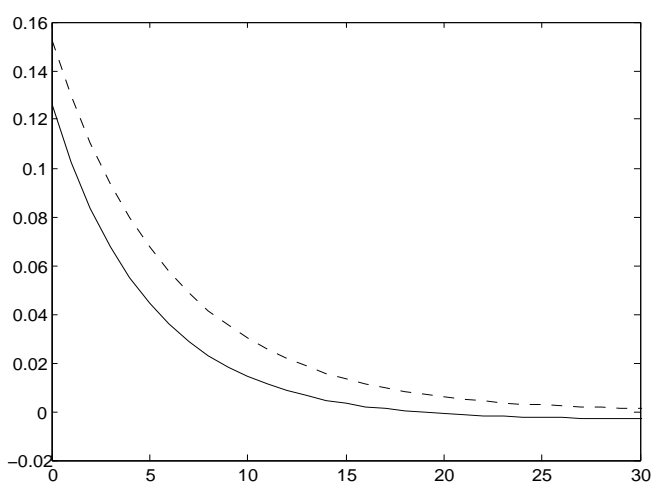

(f) Interest Rate $R_{t}$

Figure 2. Dynamic responses to a permanent shock with KPR preferences. 


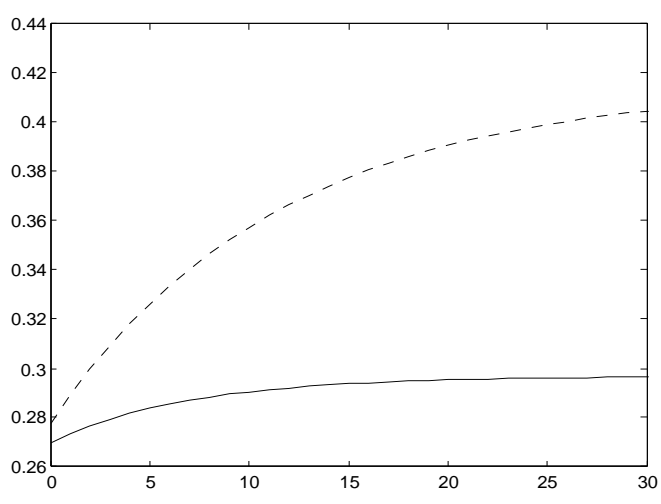

(g) Aggregate Output $Y_{t}$

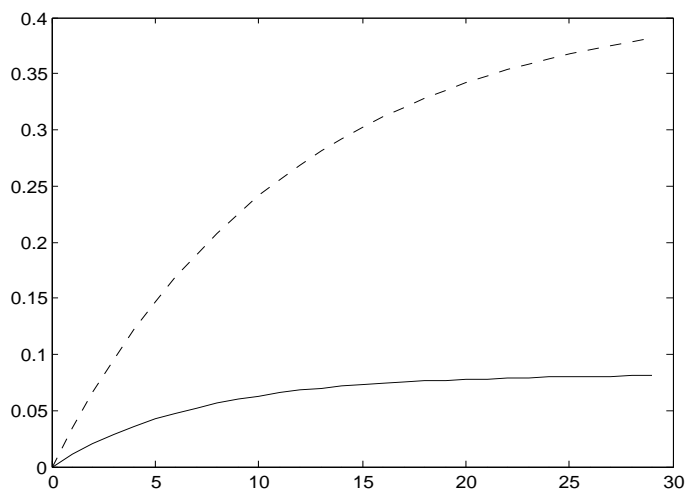

(i) Capital-Labor Ratio $K_{t} / N_{t}$

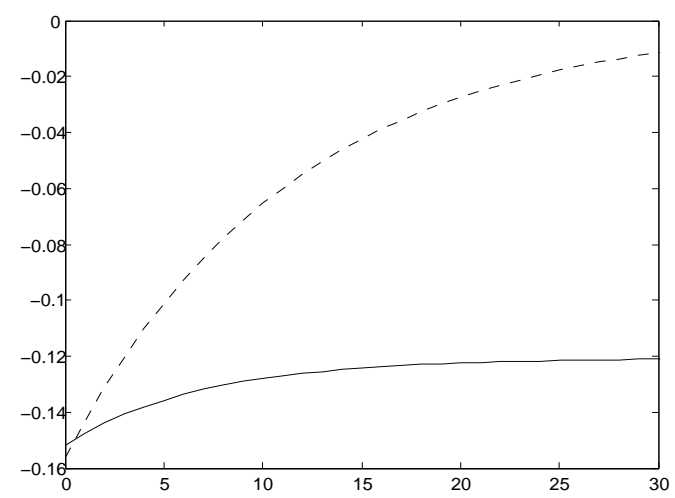

(k) Labor Productivity $Y_{t} / N_{t}$

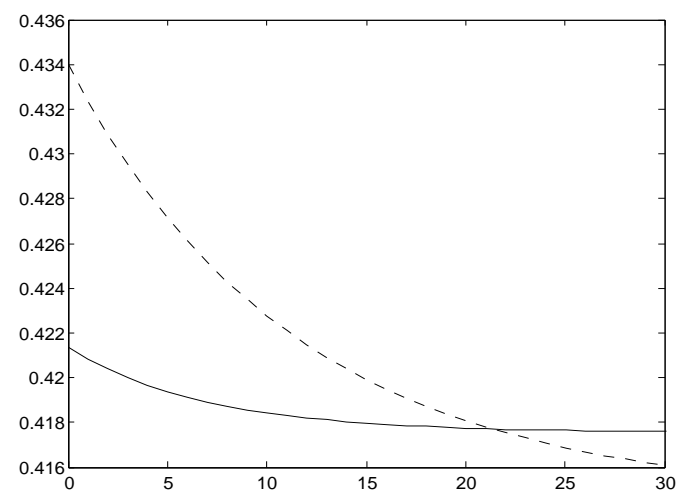

(h) Aggregate Employment $N_{t}$

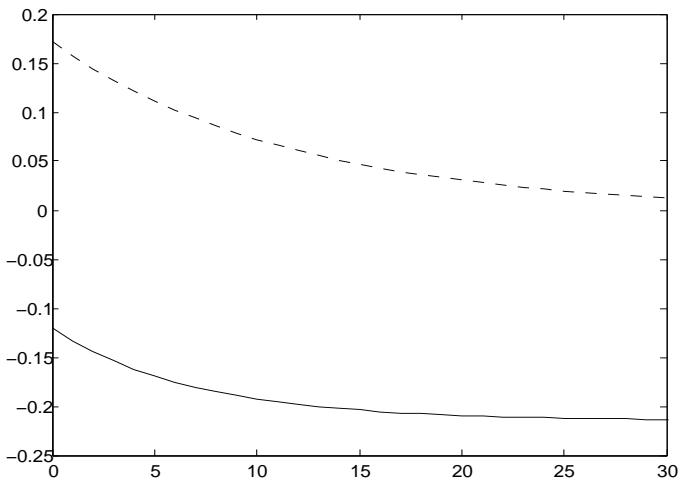

(j) Investment Rate $I_{t} / Y_{t}$

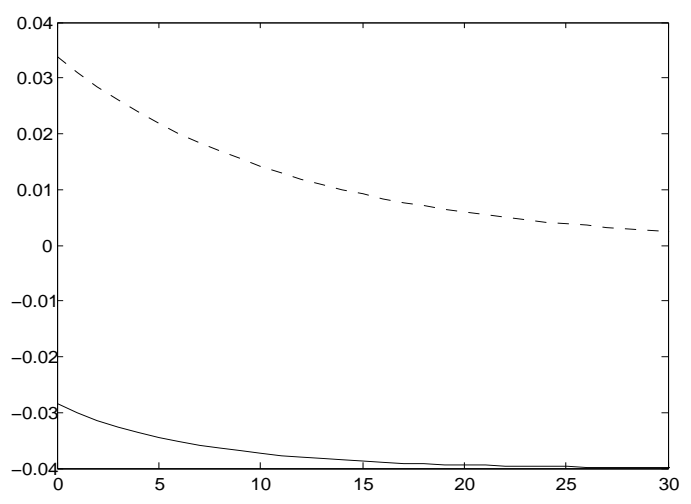

(l) Interest Rate $R_{t}$

Figure 3. Dynamic responses to a permanent shock with hand-to-mouth agents. 
employment and output stimulus of a permanent increase in government spending is weaker under incomplete markets than under complete markets. And whereas we already knew this for the long-run response of the economy, now we see that the same is true for its short-run response.

This picture holds for both the economy with KPR preferences and the one with hand-to-mouth workers. But there are also some interesting differences between the two. The mitigating effect of incomplete markets on the employment and output stimulus of government spending is much stronger in the economy with hand-to-mouth workers. As a result, whereas the short-run effects of higher government spending on the investment rate and the interest are positive under complete markets in both economies, and whereas these effects remain positive under incomplete markets in the economy with KPR preferences, they turn negative under incomplete markets in the economy with hand-to-mouth workers.

To understand this result, consider for a moment the benchmark model, where there are no handto-mouth workers and labor supply is completely inelastic. Under complete markets, a permanent change in government spending would be absorbed one-to-one in private consumption, leaving investment and interest rates completely unaffected in both the short- and the long-run. Under incomplete markets, instead, investment and the interest rate would fall on impact, as well as in the long run. Allowing labor supply to increase in response to the fiscal shock ensures that investment and the interest rate jump upwards under complete markets. However, as long as the response of labor supply is weak enough, the response of investment and the interest rate can remain negative under incomplete markets.

As a final point of interest, we calculate the welfare cost, in terms of consumption equivalent, associated with a permanent $1 \%$ increase in government spending. Under complete markets, welfare drops by $0.2 \%$, whereas under incomplete markets it drops by $0.6 \%$. In other words, the welfare cost of an increase in government spending is three times higher under incomplete markets than under complete markets. ${ }^{30}$

To recap, the quantitative results presented here indicate that a modest level of uninsured idiosyncratic investment risk can have a non-trivial impact on previously reported quantitative evaluations of fiscal policy. Note in particular that our quantitative economy with KPR preferences is directly comparable to two classics in the related literature, Aiyagari, Christiano and Eichenbaum (1992) and Baxter and King (1993). Therefore, further investigating the macroeconomic effects of fiscal shocks in richer quantitative models with financial frictions appears to be a promising direction for future research.

\footnotetext{
${ }^{30}$ Here we have assumed that government consumption has no welfare benefit, but this should not be taken literally: nothing changes if $G_{t}$ enters separably in the utility of agents.
} 


\section{Conclusion}

This paper revisits the macroeconomic effects of government consumption in an incomplete-markets version of the neoclassical growth model. Incomplete markets make individual investment sensitive to individual wealth for given prices. It follows that an increase in government spending can crowdout private investment simply by reducing disposable income. As a result, market incompleteness can seriously upset the supply-side effects of fiscal shocks: an increase in government consumption, even if financed with lump-sum taxation, tends to reduce capital intensity, labor productivity, and wages in both the short-run and the long-run. For plausible parameterizations of the model, these results appear to have not only qualitative but also quantitative content.

These results might, or might not, be bad news for the ability of the neoclassical paradigm to explain the available evidence regarding the macroeconomic effects of fiscal shocks. However, the goal of this paper was not to study the ability of an incomplete-market variant of the neoclassical growth model to match the relevant data. Rather, the goal was to identify a mechanism through which incomplete markets modify the response of the economy to fiscal shocks.

This mechanism was the dependence of individual investment on individual wealth. In our model, this property originated from uninsured idiosyncratic investment risk combined with diminishing absolute risk aversion. Borrowing constraints would lead to similar sensitivity of investment to wealth (or cash flow). Also, this mechanism need not depend on whether prices are flexible (as in the neoclassical paradigm) or sticky (as in the Keynesian paradigm). The key insights of this paper are thus clearly more general than the specific model we employed-but the quantitative importance of these insights within richer models of the macroeconomy is an open question.

An important aspect left outside our analysis is the optimal financing of government expenditures. In this paper, as in much of the related literature, we assumed that the increase in government spending is financed with lump-sum taxation, only because we wished to isolate wealth effects from tax distortions. Suppose, however, that the government has access to two tax instruments, a lumpsun tax and a proportional income tax. ${ }^{31}$ Suppose further that the government chooses taxes so as to maximize ex ante utility (equivalently, a utilitarian welfare criterion) subject to its budget constraint. Clearly, with complete markets (and no inequality) it would be optimal to finance any exogenous increase in government spending with only lump-sum taxes. With incomplete markets, however, it is likely that an increase in government spending is financed with a mixture of both instruments: while using only the lump-sum tax would disproportionately affect the utility of poor agents, using both instruments permits the government to trade off less efficiency for more equality. Further exploring these issues is left for future research.

\footnotetext{
${ }^{31}$ As in Werning (2006), this might be a good proxy for more general non-linear tax schemes.
} 


\section{Appendix: Proofs}

Proof of Proposition 1. Let $J(w, t)$ denote the value function for the household's problem. The value function depends on time $t$ because of discounting as well as because the price sequence $\left\{\omega_{t}, R_{t}\right\}_{t \in[0, \infty)}$ need not be stationary. However, the value function does not depend on $i$, because households have identical preferences, they have access to the same technology, and they face the same sequence of prices and the same stochastic process for idiosyncratic risk. The Bellman equation that characterizes the value function is given by

$$
0=\max _{m, \phi}\left\{z(m w, J(w, t))+\frac{\partial J}{\partial t}(w, t)+\frac{\partial J}{\partial w}(w, t)\left[\phi \bar{r}_{t}+(1-\phi) R_{t}-m\right] w+\frac{1}{2} \frac{\partial^{2} J}{\partial w^{2}}(w, t) \phi^{2} w^{2} \sigma^{2}\right\} .
$$

The first term of the Bellman equation (25) captures utility from current-period consumption; the second term takes care of discounting and the non-stationarity in prices; the third term captures the impact of the mean growth in wealth; and the last term (Itô's term) captures the impact of risk.

Because of the CRRA/CEIS specification of preferences, an educated guess is that there exists a deterministic process $B_{t}$ such that

$$
J(w, t)=B_{t} \frac{w^{1-\gamma}}{1-\gamma}
$$

Because of the homogeneity of $J$ in $w$, the Bellman equation then reduces to

$$
0=\max _{m, \phi}\left\{z(m, J(1, t))+\frac{\partial J}{\partial t}(1, t)+\frac{\partial J}{\partial w}(1, t)\left[\phi \bar{r}_{t}+(1-\phi) R_{t}-m\right]+\frac{1}{2} \frac{\partial^{2} J}{\partial w^{2}}(1, t) \phi^{2} \sigma^{2}\right\},
$$

so that the optimal $m$ and $\phi$ are independent of $w$. Using (5) and (26), the above becomes

$$
0=\max _{m, \phi}\left\{\frac{\beta}{1-1 / \theta}\left[B_{t}^{\frac{1 / \theta-1}{1-\gamma}} m^{1-1 / \theta}-1\right]+\frac{\dot{B}_{t} / B_{t}}{1-\gamma}+\left[\phi \bar{r}_{t}+(1-\phi) R_{t}-m\right]-\frac{1}{2} \gamma \phi^{2} \sigma^{2}\right\} .
$$

The first order condition for $\phi$ gives

$$
\phi_{t}=\frac{\bar{r}_{t}-R_{t}}{\gamma \sigma^{2}}
$$

while the the first order condition for $m$ gives

$$
m_{t}=\beta^{\theta} B_{t}^{\frac{1-\theta}{1-\gamma}}
$$


Substituting this into (28), using the definition of $\hat{\rho}_{t}$, and rearranging, we get

$$
0=\frac{\beta^{\theta} B_{t}^{\frac{1-\theta}{1-\gamma}}-\theta \beta}{\theta-1}+\frac{\dot{B}_{t} / B_{t}}{1-\gamma}+\hat{\rho}_{t} .
$$

This ODE, together with the relevant transversality condition, determines the process for $B_{t}$. Using (30), this is equivalent to

$$
\frac{\dot{m}_{t}}{m_{t}}=m_{t}+(\theta-1) \hat{\rho}_{t}-\theta \beta,
$$

which is the Euler condition (13).

Proof of Proposition 2. Since aggregate labor demand is $\int_{i} n_{t}^{i}=\bar{n}\left(\omega_{t}\right) K_{t}$ and aggregate labor supply is 1 , the labor market clears if and only if $\bar{n}\left(\omega_{t}\right) K_{t}=1$. It follows that the equilibrium wage satisfies $\omega_{t}=F_{L}\left(K_{t}, 1\right)$ and, similarly, the equilibrium mean return to capital satisfies $\bar{r}_{t}=$ $F_{K}\left(K_{t}, 1\right)-\delta$. The bond market, on the other hand, clears if and only if $0=\left(1-\phi_{t}\right) W_{t}+H_{t}$. Combining this with $K_{t}=\phi_{t} W_{t}$ gives condition (17).

Combining the intertemporal government budget with the definition of human wealth, we get

$$
H_{t}=h_{t}=\int_{t}^{\infty} e^{-\int_{t}^{s} R_{j} d j}\left(\omega_{s}-G_{s}\right) d s .
$$

Expressing this in recursive form gives condition (16).

Combining the latter with $K_{t}+H_{t}=W_{t}$ and $\dot{W}_{t}=\rho W_{t}-C_{t}$, we have $\dot{K}_{t}=\dot{W}_{t}-\dot{H}_{t}=$ $\left(\rho_{t} W_{t}-C_{t}\right)-\left(R_{t} H_{t}-\omega_{t}+G_{t}\right)$. Using $\rho_{t} W_{t}=\bar{r}_{t} \phi_{t} W_{t}+R_{t}\left(1-\phi_{t}\right) W_{t}=\bar{r}_{t} K_{t}+R_{t} H_{t}$, we get $\dot{K}_{t}=\bar{r}_{t} K_{t}+\omega_{t}-C_{t}-G_{t}$. Together with the fact, in equilibrium, $\bar{r}_{t} K_{t}+\omega_{t}=F\left(K_{t}, 1\right)-\delta K_{t}$, this gives condition (14), the resource constraint.

Finally, using $C_{t}=m_{t} W_{t}$, and therefore $\dot{C}_{t} / C_{t}=\dot{m}_{t} / m_{t}+\dot{W}_{t} / W_{t}$ together with $\dot{W}_{t}=\rho_{t} W_{t}-$ $C_{t}=\left(\rho_{t}-m_{t}\right) W_{t}$ and (13), gives condition (15), the aggregate Euler condition.

Proof of Proposition 3. First, we derive the two equations characterizing the steady state $K$ and $R$. In steady state, the Euler condition gives

$$
0=\theta(\rho-\beta)-(\theta-1) \frac{1}{2} \gamma \sigma^{2} \phi^{2}
$$

where

$$
\rho=R+\frac{\left[f^{\prime}(K)-\delta-R\right]^{2}}{\gamma \sigma^{2}} \text { and } \phi=\frac{f^{\prime}(K)-\delta-R}{\gamma \sigma^{2}} .
$$

Combining and solving for $f^{\prime}(K)$ gives condition (18). Condition (19), on the other hand, follows directly from (16) and (17).

Next, we prove existence and uniqueness of the steady state. Let $\mu(R)$ and $\phi(R)$ denote, 
respectively, the risk premium and the fraction of effective wealth held in capital, when $K$ is given by (18):

$$
\mu(R) \equiv \sqrt{\frac{2 \theta \gamma \sigma^{2}}{1+\theta}(\beta-R)} \quad \text { and } \quad \phi(R) \equiv \sqrt{\frac{2 \theta}{\gamma \sigma^{2}(1+\theta)}(\beta-R)} .
$$

Note that $\mu^{\prime}(R)<0$ and $\phi^{\prime}(R)<0$. Next, let $K(R)$ denote the solution to (18), or equivalently

$$
K(R)=\left[\frac{\mu(R)+\delta+R}{\alpha}\right]^{\frac{1}{\alpha-1}}
$$

Finally, let

$$
D(R ; g) \equiv(1-\alpha-g) \frac{K(R)^{\alpha-1}}{R}-\frac{1-\phi(R)}{\phi(R)} .
$$

This represents the ratio of the net foreign asset position to domestic capital of an open economy that faces an exogenous interest rate $R \in(0, \beta)$. (Note that we have used $\omega=(1-\alpha) Y, G=g Y$, and $Y=f(K)=K^{\alpha}$, where $\alpha>0, g \geq 0$, and $\alpha+g<1$.) To establish existence and uniqueness of the steady state (for the closed economy), it suffices to show that there exists a unique $R$ that solves $D(R ; g)=0$.

Fix $g$ henceforth, and consider the limits of $D$ as $R \rightarrow 0^{+}$and $R \rightarrow \beta^{-}$. Note that $\mu(0)=$ $\left(\frac{2 \theta \gamma \sigma^{2}}{1+\theta} \beta\right)^{1 / 2}$ is finite and hence both $\phi(0)$ and $K(0)$ are finite. It follows that

$$
\lim _{R \rightarrow 0^{+}} D(R ; g)=(1-\alpha-g) K(0)^{\alpha-1} \lim _{R \rightarrow 0^{+}} \frac{1}{R}-\frac{1}{\phi(0)}+1=+\infty
$$

Furthermore, $\mu(\beta)=0$, implying $\phi(\beta)=0$ and $K(\beta)=K_{\text {compl }} \equiv\left(f^{\prime}\right)^{-1}(\beta)$ is finite. It follows

$$
\lim _{R \rightarrow \beta^{-}} D(R ; g)=(1-\alpha-g) K(\beta)^{\alpha-1} \frac{1}{\beta}-\lim _{R \rightarrow \beta^{-}} \frac{1}{\phi(R)}+1=-\infty .
$$

These properties, together with the continuity of $D(R)$ in $R$, ensure the existence of an $R \in(0, \beta)$ such that $D(R)=0$.

If we now show that $D(R ; g)$ is strictly decreasing in $R$, then we also have uniqueness. To show this, note that from (33),

$$
\frac{\partial D}{\partial R}=(1-\alpha-g) \frac{K(R)^{\alpha-1}}{R^{2}}\left[(\alpha-1) R \frac{K^{\prime}(R)}{K(R)}-1\right]+\frac{\phi^{\prime}(R)}{\phi(R)^{2}} .
$$

Now note that

$$
K^{\alpha-1}=\frac{f^{\prime}(K)}{\alpha}, \quad \frac{K^{\prime}}{K}=\frac{1}{\alpha-1} \frac{\mu^{\prime}+1}{f^{\prime}(K)}, \quad \text { and } \quad \frac{\phi^{\prime}}{\phi^{2}}=\frac{\gamma \sigma^{2} \mu^{\prime}}{\mu^{2}}
$$


where we suppress the dependence of $K, \mu$, and $\phi$ on $R$ for notational simplicity. It follows that

$$
\begin{aligned}
\frac{\partial D}{\partial R} & =\frac{1-\alpha-g}{\alpha} \frac{f^{\prime}(K)}{R^{2}}\left[R \frac{\mu^{\prime}+1}{f^{\prime}(K)}-1\right]+\frac{\gamma \sigma^{2} \mu^{\prime}}{\mu^{2}}= \\
& =\frac{1-\alpha-g}{\alpha} \frac{R \mu^{\prime}+R-f^{\prime}(K)}{R^{2}}+\frac{\gamma \sigma^{2} \mu^{\prime}}{\mu^{2}}
\end{aligned}
$$

Since $\mu^{\prime}(R)<0$ and $R<f^{\prime}(K(R))$ for all $R \in(0, \beta)$, we have that $\partial D / \partial R<0$ for all $R \in(0, \beta)$, which completes the argument.

Proof of Lemma 1. Recall that (18) is equivalent to

$$
\theta(\rho-\beta)-(\theta-1) \gamma \phi^{2} \sigma^{2}=0
$$

where $\rho=\phi f^{\prime}(K)+(1-\phi) R$ and $\phi=\left(f^{\prime}(K)-R\right) / \gamma \sigma^{2}$. Applying the implicit function theorem, we get

$$
\left.\frac{\partial K}{\partial R}\right|_{(18)}=\frac{\phi-\theta(1-\phi)}{\phi(\theta+1)} \frac{1}{f^{\prime \prime}}
$$

which proves that:

$$
\frac{\partial K_{1}}{\partial R}<0 \Leftrightarrow \theta<\frac{\phi}{1-\phi} .
$$

On the other hand, from (19), using $\phi=\left(f^{\prime}(K)-R\right) / \gamma \sigma^{2}, f^{\prime}(K)=\alpha K^{\alpha-1}$ and $\omega-G=$ $(1-\alpha-g) K^{\alpha}$, we get

$$
\left.\frac{\partial K}{\partial R}\right|_{(19)}=-\frac{(1-\alpha) \frac{K^{\alpha-1}}{R^{2}}+\frac{\gamma \sigma^{2}}{\mu^{2}}}{\frac{(1-\alpha)^{2}}{R} K^{\alpha-2}+\frac{\gamma \sigma^{2}}{\mu^{2}}(1-\alpha) \frac{f^{\prime}}{K}}<0
$$

which proves that $\partial K_{2} / \partial R<0$ always.

Proof of Proposition 4. From (33), we have that $\partial D / \partial g<0$. Together with the property that $\partial D / \partial R<0$, this implies that the steady-state $R$ necessarily decreases with $g$. The impact of $g$ on the steady-state $K$ then follows from the fact that $K_{1}(R)$, defined by (18), does not depend on $g$ and is increasing/decreasing in $R$ if and only if $\theta$ is higher/lower than $\phi /(1-\phi)$. 


\section{References}

Aït-Sahalia, Y., Parker, J. A., M. Yogo (2001), "Luxury Goods and the Equity Premium," NBER, Working Paper 8417.

Aiyagari, S. R. (1994), "Uninsured Idiosyncratic Risk and Aggregate Saving," Quarterly Journal of Economics 109, 659-684.

Aiyagari, S. R., Christiano, L., and M. Eichenbaum (1992), "The Output, Employment, and Interest Rate Effects of Government Consumption," Journal of Monetary Economics 30, 7386.

Angeletos, G.-M. (2007), "Uninsured Idiosyncratic Investment Risk and Aggregate Saving," Review of Economic Dynamics 10, 1-30.

Angeletos, G.-M., and L.-E. Calvet (2006), "Idiosyncratic Production Risk, Growth, and the Business Cycle," Journal of Monetary Economics 53, 1095-1115.

Barro, R. J. (1981), "Output Effects of Government Purchases," Journal of Political Economy 89, 1086-1121.

Barro, R. J. (1989), "The Ricardian Approach to Budget Deficits," Journal of Economic Perspectives $3,37-54$.

Baxter, M., and R. G. King (1993), "Fiscal Policy in General Equilibrium," American Economic Review 83, 315-334.

Blundell, R., and T. MaCurdy (1999), "Labour Supply: A Review of Alternative Approaches," Handbook of Labor Economics, 3, O. Ashenfelter and D. Card (eds).

Buera, F., and T. Shin (1999), "Financial Frictions and the Persistence of History: a Quantitative Exploration," Working Paper.

Cagetti, M., and M. De Nardi (2006), "Entrepreneurship, Frictions, and Wealth," Journal of Political Economy 114, 835-870.

Campbell, J., and N.G. Mankiw (1989), "Permanent Income, Current Income, and Consumption," NBER Macroeconomics Annual 1989.

Card, D. (1990), "Intertemporal Labor Supply: An Assessment," Princeton University, Working Paper 269.

Carroll, C. (2000), "Portfolios of the Rich," NBER, Working Paper 430.

Christiano, L. J., and M. Eichenbaum (1992), "Current Real-Business-Cycle Theories and Aggregate Labor Market Fluctuations," American Economic Review 82, 430-450. 
Covas, F. (2006), "Uninsured Idiosyncratic Production Risk with Borrowing Constraints," Journal of Economic Dynamics and Control 30, 2167-2190.

Duffie, D., and L. G. Epstein (1992), "Stochastic Differential Utility," Econometrica 60, 353-394.

Gentry, W. M., and R. G. Hubbard (2000), "Entrepreneurship and Household Saving," NBER, working paper 7894 .

Greenwood, J., Hercowitz, Z., and G. Huffman (1988), "Investment, Capacity Utilization and the Real Business Cycle," American Economic Review 78, 402-417.

Gruber, J. (2005), "A Tax-Based Estimate of the Elasticity of Intertemporal Substitution," NBER, working paper 11945.

Guvenen, F. (2006), "Reconciling Conflicting Evidence on the Elasticity of Intertemporal Substitution: A Macroeconomic Perspective," Journal of Monetary Economics 53, 1451-1472.

Hall, R. (1980), "Stabilization Policy and Capital Formation," American Economic Review 70, $156-63$.

Hall, R. (1988), "Intertemporal Substitution in Consumption," Journal of Political Economy 96, 339-357.

Hausman, J. (1981), "Labor Supply: How taxes affect Economic Behavior," Tax and the Economy, H. Aaron and J. Pechman (eds.), Brookings Institute, Washigton DC.

Heathcote, J. (2005), "Fiscal Policy with Heterogeneous Agents and Incomplete Markets," Review of Economic Studies 72, 161-188.

Huggett, M. (1997), "The One-Sector Growth Model With Idiosyncratic Shocks," Journal of Monetary Economics 39, 385-403.

Jaimovich, N., and S. Rebelo (2006), "Can News About the Future Drive the Business Cycle?, " NBER, Working Paper 12537.

King, R. G., and S. Rebelo (1990), "Public Policy and Economic Growth: Developing Neoclassical Implications," Journal of Political Economy 98, S126-S150.

King, R. G., Plosser, C., and S. Rebelo (1988), "Production, Growth and Business Cycles: I. the Basic Neoclassical Model," Journal of Monetary Economics 21, 195-232.

Krusell, P., and A.A. Smith (1998), "Income and Wealth Heterogeneity in the Macroeconomy," Journal of Political Economy 106, 867-896.

MaCurdy, T. (1981), "An Empirical Model of Labor Supply in a Life-Cycle Setting," Journal of Political Economy 86, 1059-1085. 
Malloy, C. J., Moskowitz, T. J., and A. Vissing-Jørgensen (2006), "Long Run Stockholder Consumption Risk and Asset Returns," Working Paper.

Mankiw, G. N., Rotemberg, J., and L. H. Summers (1985), "Intertemporal Substitution in Macroeconomics," Quarterly Journal of Economics 100, 1059-1085.

Mankiw, G. N., and S. P. Zeldes (1991), "The Consumption of Stockholders and Nonstockholders," Journal of Financial Economics 29, 97-112.

McGrattan, E., and L. E. Ohanian (1999), "The Macroeconomic Effects of Big Fiscal Shocks: The Case of World War II," Federal Reserve Bank of Minneapolis, Working Paper 599.

McGrattan, E., and L. E. Ohanian (2006), "Does Neoclassical Theory Account for the Effects of Big Fiscal Shocks: Evidence from World War II," Federal Reserve Bank of Minneapolis, Research Department Staff Report 315.

Meh, C., and V. Quadrini (2006), "Endogenous Market Incompleteness with Investment Risks," Journal of Economic Dynamics and Control 30, 2143-2165.

Moskowitz, T., and A. Vissing-Jørgensen (2002), "The Returns to Entrepreneurial Investment: A Private Equity Premium Puzzle?," American Economic Review 92, 745-778.

Mulligan, C. (2002), "Capital, Interest, and Aggregate Intertemporal Substitution," NBER Working Paper 9373.

Obstfeld, M. (1994), "Risk-Taking, Global Diversification, and Growth," American Economic Review 84, 1310-1329.

Quadrini, V. (2000), "Entrepreneurship, Saving, and Social Mobility," Review of Economic Dynamics 3, 1-40.

Vissing-Jørgensen, A. (2002), "Limited Asset Market Participation and the Elasticity of Intertemporal Substitution," Journal of Political Economy 110, 825-853.

Vissing-Jørgensen, A., and O. Attanasio (2003), "Stock-Market Participation, Intertemporal Substitution, and Risk Aversion," American Economic Review 93, 383-391.

Werning, I. (2006), "Optimal Fiscal Policy with Redistribution, " Quarterly Journal of Economics, forthcoming. 